\title{
Reduction kinetics of lanthanum ferrite perovskite for the production of synthesis gas by chemical-looping methane reforming
}

\author{
Xiaoping Dai ${ }^{\text {a,* }}$, Jie Cheng ${ }^{\mathrm{b}}$, Zhanzhao $\mathrm{Li}^{\mathrm{a}}$, Mengzhao Liu ${ }^{\mathrm{a}}$, Yangde Ma ${ }^{\mathrm{a}}$, Xin Zhang ${ }^{\mathrm{a}}$ \\ a State Key Laboratory of Heavy Oil Processing, China University of Petroleum, Beijing 102249, PR China \\ ${ }^{\mathrm{b}}$ Research Center for Eco-Environmental Sciences, Chinese Academy of Sciences, Beijing 100085, PR China
}

\section{H I G H L I G H T S}

- Kinetic of reduction of $\mathrm{LaFeO}_{3}$ oxygen carrier for CLMR was determined.

- The 2-D nuclei growth model best describes solids conversion evolution with time.

- Model validity is verified by continuous flow reaction and sequential redox cycles.

- Activation energies for the rate constants were estimated.

\section{A R T I C L E I N F O}

\section{Article history:}

Received 12 September 2015

Received in revised form

29 June 2016

Accepted 8 July 2016

Available online 9 July 2016

\section{Keywords:}

Chemical-looping methane reforming

Synthesis gas

$\mathrm{LaFeO}_{3}$ perovskite

Oxygen carrier

Reduction kinetics
G R A P H I C A L A B S T R A C T

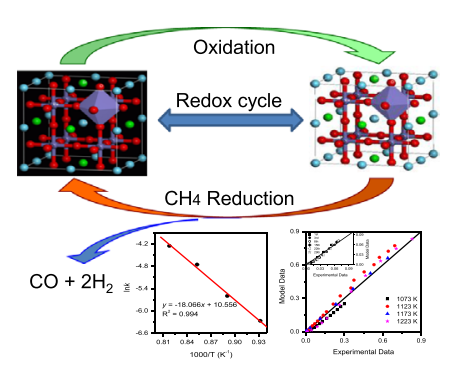

\begin{abstract}
A B S T R A C T
The reduction kinetics of $\mathrm{LaFeO}_{3}$ oxygen carrier for the production of synthesis gas by chemical-looping methane reforming (CLMR) is investigated in the present work. The stoichiometric relationship between oxygen carrier and methane in chemical-looping process is established by temperature programmed surface reaction (TPSR), X-ray diffraction (XRD), scanning electron microscopy (SEM), transmission electron microscopy (TEM) and X-ray photoelectron spectroscopy (XPS) characterization. The effects of reduction conditions, namely, gas to solid molar ratio, temperature and sequential redox reaction on the oxygen carrier conversion are investigated. The results from Hancock and Sharp method suggest that the phase boundary control is likely to be dominant. The power law model (PLM), shrinking core model (SCM), as well as nucleation and nuclei growth model (NNGM) are considered to interpret the reduction kinetics of $\mathrm{LaFeO}_{3}$ with methane to synthesis gas. The obtained results show that the 2-D NNGM best describes the experimental data providing parameters with adequate statistical fitting indicators. The model validity is also verified by the data from continuous flow reaction and sequential redox cycles to simulate chemical-looping methane reforming process. The apparent activation energy is estimated and compared with values from the literature data.
\end{abstract}

(c) 2016 Published by Elsevier Ltd.

\section{Introduction}

Efficient and environmental friendly conversion of methane into synthesis gas (syngas, $\mathrm{CO}+\mathrm{H}_{2}$ ) is a topic of practical relevance for the production of hydrogen, chemicals, and synthetic fuels

\footnotetext{
* Corresponding author.

E-mail address: daixp@cup.edu.cn (X. Dai).
}

(Tanaka et al., 2009). At present, the efficiencies of the steam methane reforming processes are limited owing to the intensely endothermic reaction and high steam to methane ratio required. One of the potentially attractive ways of syngas production is partial oxidation of methane (POM) process without external heat supply. However, a major barrier for this process is the rapid catalyst deactivation caused by coke formation, mostly for nickelbased catalysts (Kim et al., 2009; Enger et al., 2008). Another 


\begin{tabular}{|c|c|c|c|}
\hline \multicolumn{2}{|c|}{ Nomenclature } & $p_{\mathrm{CH} 4}$ & partial pressure of methane (kPa) \\
\hline A & pre-exponential factor (model specific) & $-r_{\mathrm{CH} 4 \mathrm{robs}}^{\prime}$ & observed rate of the reduction reaction $(\mathrm{mol} / \mathrm{g} / \mathrm{s})$ \\
\hline$C_{\mathrm{CH} 40}$ & initial concentration of methane $\left(\mathrm{mol} / \mathrm{m}^{3}\right)$ & $\mathrm{R}$ & gas constant $(\mathrm{J} / \mathrm{mol} / \mathrm{K})$ \\
\hline$C_{C H 4 b}$ & concentration of methane in the bulk fluid $\left(\mathrm{mol} / \mathrm{m}^{3}\right)$ & $S_{e x}$ & external surface area per gram of sample $\left(\mathrm{m}^{2} / \mathrm{g}\right)$ \\
\hline $\mathrm{C}_{\mathrm{CH} 4 \mathrm{~s}}$ & $\begin{array}{l}\text { concentration of methane at the surface of the oxygen } \\
\text { carrier }\left(\mathrm{mol} / \mathrm{m}^{3}\right)\end{array}$ & $\begin{array}{l}\mathrm{T} \\
W_{\mathrm{CH} 4 \mathrm{r}}\end{array}$ & $\begin{array}{l}\text { temperature }(\mathrm{K}) \\
\text { radial flux of methane }\left(\mathrm{mol} / \mathrm{m}^{2} \mathrm{~s}\right)\end{array}$ \\
\hline$C_{\mathrm{WP}}$ & Weisz-Prater parameter & $w_{\mathrm{p}}$ & mass of oxide carrier loaded into the reactor $(\mathrm{g})$ \\
\hline$D$ & diameter of oxygen carrier $(\mu \mathrm{m})$ & $X_{\mathrm{CH} 4}$ & conversion of methane (\%) \\
\hline$D_{\mathrm{AB}}$ & diffusivity for methane in argon $\left(\mathrm{m}^{2} / \mathrm{s}\right)$ & A & conversion of oxygen carrier (\%) \\
\hline$D_{\text {eff }}$ & effective diffusivity $\left(\mathrm{m}^{2} / \mathrm{s}\right)$ & $\beta$ & constant which is partially dependent upon the nu- \\
\hline Ea & activation energy $(\mathrm{kJ} / \mathrm{mol})$ & & cleation frequency and rate of grain growth \\
\hline$f(\alpha)$ & reaction model & $\mathrm{P}$ & density of oxygen carrier $\left(\mathrm{kg} / \mathrm{m}^{3}\right)$ \\
\hline$f\left(p_{C H 4}\right)$ & function of methane partial pressure in the gas phase & $k$ & rate constant (model specific) \\
\hline & integral form of the reaction model & $n$ & Avrami constant \\
\hline & molecular weight of oxygen carrier $(\mathrm{kg} / \mathrm{mol})$ & $T$ & reduction time $(\mathrm{s})$ \\
\hline$N_{\mathrm{CH} 4,0}$ & initial number of moles injected into the reactor (mol) & & \\
\hline
\end{tabular}

challenge by POM process is the costly air separation unit for pure oxygen and high possibility of gas explosion by directly contact of oxygen and methane at high temperature (Choudhary and Choudhary, 2008; Rostrup-Nielsen et al., 2008). Applying the chemical looping methane reforming (CLMR) concept to POM enables an opportunity to resolve the two issues by spatially separating $\mathrm{CH}_{4}$ conversion into two half-steps over the fuel reactor and air reactor. The CLMR process eliminates the expensive air separation and mixing unit, and fulfills the heat balance between the endothermic reduction reaction in fuel reactor and exothermic oxidation reaction in air reactor by the circulating oxygen carrier (de Diego et al., 2008; Dueso et al., 2012). The reduction of oxygen carrier by methane shows the potential for a new green technology of syngas production without using any catalyst and its deactivation problem.

The key issue for large-scale application of CLMR process is the oxygen carrier with suitable properties. Several critical screening criteria have been addressed which include reversible oxygen storage capacity, reactivity toward both fuel and oxidant, attrition resistance, agglomeration and carbon deposition, as well as the environmental and economic impacts (Tang et al., 2015). It is generally accepted that $\mathrm{NiO}$ possesses sufficient activity among the transient metal oxides, but the carbon formation with Ni-based oxygen carriers is prominent in chemical-looping methane combustion (CLMC), and thus is observed mostly at the end of reduction reactions (Rydén et al., 2008a; Cabello et al., 2014a). The challenge of $\mathrm{NiO}$ based redox catalysts, however, is their high tendency for coke formation, high cost, and health concerns (Adanez et al., 2012; Neal et al., 2014). Fe-based oxides have the advantages of being cheaper, low agglomeration, high melting point and more environmentally benign (Cabello et al., 2014a; Adanez et al., 2012; Neal et al., 2014, 2015; Shafiefarhood et al., 2014; Galinsky et al., 2015). However, iron oxide based redox catalysts are not particularly active for methane oxidation (Cabello et al., 2014a; Shafiefarhood et al., 2014), and tend to have low selectivity toward methane partial oxidation. Notably, the reactivity and selectivity in CLMR process can be improved by combining different materials to bring synergetic effect or form solid solution (spinel, perovskite, et al.) (Cabello et al., 2014a; Neal et al., 2014, 2015; Bhavsar and Veser, 2013; Zhu et al., 2014; Chen et al., 2014). As mentioned above, although many work to increase the reactivity and syngas selectivity have been carried out for a long time, the reduction kinetics of oxygen carriers using methane as fuel at representative conditions of CLMR system has been seldom investigated (Dueso et al., 2012; Rashidi et al., 2013a, 2013b). Many models have been used to describe the conversiontime profiles of noncatalytic gas-solid reactions in the literature. The most frequently used models are the shrinking core model (SCM) and nucleation and nuclei growth model (NNGM), which have also been done in the past about the reduction kinetic determination of supported or un-supported metal oxides for CLMC (Hossain and de Lasa, 2008; Sedor et al., 2008; Monazam et al., 2013; Nasr et al., 2014; Lario et al., 2013; Hossain et al., 2010a; Hossain and de Lasa, 2010b; Hossain and de Lasa, 2007). However, the application of the experience achieved for CLMC can not be directly applied to the reactions involved in the CLMR process for several reasons: (i) the composition and type of oxygen carriers are distinct from CLMC; (ii) the oxidized and reduced state can not be the same as that for CLMC; (iii) the experimental condition (e.g. temperature, gas composition, gas to solid ratio, desired product) are usually different with those required for CLMR. Rashidi et al. (2013b) found only a small induction period in the reduction of unsupported nickel oxide with methane, and neglected it in the modified grain model for spherical grain geometry. However, an induction period was indeed observed during the reduction of iron ore, Ni-based oxygen carrier and $\mathrm{LaMnO}_{3}$ perovskite (Nasr and Plucknett, 2014; Sarshar et al., 2013; Zafar et al., 2007). Sarshar and Kaliaguine (2013) found that both SCM and NNGM yield poor fits of the reduction kinetic data, and the introduction of an induction time in kinetic model will improve the valid estimation. These results implied that it is very necessary to determine different reduction kinetic parameters for each oxygen carrier, which depends on the oxygen-transport capacity and reactivity of the oxygen carrier.

As excellent reduction-oxidation properties, high reversible oxygen mobility, and chemical and thermal stability, perovskitebased oxygen carriers become more attractive in CLMR process (Mihai et al., 2012; Dai et al., 2006a, 2006b; García et al., 2010; Mihai et al., 2011; Nalbandian et al., 2011; Rydén et al., 2008b). The desirable properties of perovskite (e.g. metal ions, binding energy and oxygen diffusion in the lattice) can be tailored by selectively changing A and B cations (Mihai et al., 2012). Recently, perovskitetype $\mathrm{LaFeO}_{3}$-based oxygen carriers and its substitution in $\mathrm{A}$ and/or B sites exhibit high catalytic activity with high selectivity towards $\mathrm{CO} / \mathrm{H}_{2}$ in CLMR process (Mihai et al., 2012; Dai et al., 2006a, 2006b; García et al., 2010; Mihai et al., 2011; Nalbandian et al., 2011; Rydén et al., 2008b; Zeng et al., 2003), which fuels the desire to investigate the reduction kinetics of $\mathrm{LaFeO}_{3}$ oxygen carriers with methane in order to estimate the relevant design parameters for CLMR process, e.g., solids circulation flow rate or solids 
inventory in the fuel reactor. Herein, the reduction kinetics of $\mathrm{LaFeO}_{3}$ oxygen carrier under different reduction temperature and gas to solid molar ratios were investigated. Three kinetic models were compared on the bases of their ability to accurately describe the experimental data: the power-law relation, the shrinking core model, and the nucleation and nuclei growth model. The kinetic data obtained in this work will be implemented in a reactor model for the prediction, design and optimization purposes of a CLMR system with $\mathrm{LaFeO}_{3}$ perovskite as the oxygen carrier.

\section{Experimental}

\subsection{Preparation of oxygen carrier}

The $\mathrm{LaFeO}_{3}$-perovskite oxide was prepared by the sol-gel method. Typically, the $\mathrm{La}$ and $\mathrm{Fe}$ nitrates $(\mathrm{La} / \mathrm{Fe}=1.0$, atom ratio) were completely dissolved in deionized water. Then, glycine solution was added dropwise to the mixed solution with stirring at a ratio $\mathrm{NH}_{3} / \mathrm{NO}_{3}{ }^{-}=1.05$. The mixed solution was agitated at 353$363 \mathrm{~K}$ to form a viscous gel, and dried at $353 \mathrm{~K}$ for $24 \mathrm{~h}$. The resulted gel was placed in a stainless steel sealed vessel at $523 \mathrm{~K}$ for 30 min to obtain a brown powder precursor. The precursor was calcined at $1173 \mathrm{~K}$ for $10 \mathrm{~h}$, and then were tableted, crushed, and sieved.

\subsection{Characterization of oxygen carrier}

Powder X-ray diffraction (XRD) was performed on a ShiDU XRD-6000 diffraction with Ni-filtered $\mathrm{Cu} \mathrm{K \alpha}$ radiation. The BET surface area was $6.08 \mathrm{~m}^{2} / \mathrm{g}$ by $\mathrm{N}_{2}$ adsorption/desorption at $77 \mathrm{~K}$ using a gas sorption analyzer NOVA 1200. Investigations of the morphology were carried out on a HITACHI S-4800 scanning electron microscope (SEM) and JEOL-2100 transmission electron microscopy (TEM). The particle size distribution of the nanopowder was measured by a laser particle size analyzer (Mastersizer 2000 Particle Analyzer, Malvern Instruments Ltd.). The Xray photoelectron spectrum (XPS) was carried out on a VGESCA LAB 210 system using Mg K radiation. All binding energies were calibrated to the $\mathrm{C} 1 \mathrm{~s}$ peak at $284.6 \mathrm{eV}$.

A micromeritics chemisorb 2720 system (Micromeritics Instrument Corp.) was used to investigate oxygen desorption $\left(\mathrm{O}_{2}-\right.$ TPD) and hydrogen reduction $\left(\mathrm{H}_{2}-\mathrm{TPR}\right)$ tests. Prior to $\mathrm{O}_{2}-\mathrm{TPD}$, $125 \mathrm{mg}$ sample was pretreated in $5 \mathrm{vol} \% \mathrm{O}_{2} / \mathrm{He}$ at $423 \mathrm{~K}$ for $3 \mathrm{~h}$. Then, After cooling to room temperature, the sample was heated from room temperature to $1233 \mathrm{~K}$ at a rate of $10 \mathrm{~K} / \mathrm{min}$ in pure He. The desorbed oxygen was continuously monitored and quantified by a thermoconductivity detector (TCD). The $\mathrm{H}_{2}$-TPR was carried out on the same apparatus as in $\mathrm{O}_{2}$-TPD. $196 \mathrm{mg}$ sample was placed in a quartz reactor, pretreated under a flow of $20 \mathrm{~mL} / \mathrm{min}$ ( $20 \mathrm{vol} \% \mathrm{O}_{2}$ in $\mathrm{He}$ ) at $423 \mathrm{~K}$ for $2 \mathrm{~h}$, and cooled down to room temperature. The $\mathrm{H}_{2}$-TPR was then carried out under a $10 \mathrm{~mL} / \mathrm{min}$ flow of 5 vol\%. $\mathrm{H}_{2}$ in Ar. The temperature was increased from room temperature to $1233 \mathrm{~K}$ at a rate with a ramp of $10 \mathrm{~K} / \mathrm{min}$. The consumption of hydrogen was monitored and quantified using a TCD on the basis of the calibrations at various weight of pure $\mathrm{CuO}$. Temperature programmed surface reaction with methane $\left(\mathrm{CH}_{4}-\right.$ TPSR) was performed on a quartz fixed-bed microreactor $(6 \mathrm{~mm}$ i. d.) packed with $250 \mathrm{mg}$ samples. The sample was dehydrated for $1 \mathrm{~h}$ at $423 \mathrm{~K}$ in pure $\mathrm{Ar}$, then the temperature was increased at a rate of $15 \mathrm{~K} / \mathrm{min}$ under $11 \mathrm{vol} \% \mathrm{CH}_{4}$ in Ar with a flow of $26 \mathrm{~mL} / \mathrm{min}$. The composition of the effluent gas from the reactor was monitored by an on-line quadrupole mass spectrometer.

\subsection{Reactivity tests of oxygen carrier}

In continuous flow reaction, the oxygen carrier was placed in a fixed-bed microreactor with inner diameter of $6 \mathrm{~mm}$ and a height of $580 \mathrm{~mm}$, and was heated to reaction temperature for pretreatment with $11 \mathrm{vol} \% \mathrm{O}_{2} / \mathrm{Ar}(23 \mathrm{~mL} / \mathrm{min})$ for $30 \mathrm{~min}$. Then the reactant gas ( $11 \mathrm{vol} \%$ methane in argon, $23 \mathrm{~mL} / \mathrm{min}$ ) was introduced. Sequential redox cycles were performed at $1173 \mathrm{~K}$ between reductive atmospheres ( $11 \mathrm{vol} \% \mathrm{CH}_{4}$ in $\mathrm{He}, 23 \mathrm{~mL} / \mathrm{min}$ ) and oxidative atmospheres ( $11 \mathrm{vol} \% \mathrm{O}_{2}$ in $\mathrm{Ar}, 23 \mathrm{~mL} / \mathrm{min}$ ) to simulate fuel reactor and air reactor. The offgas composition from the reactor was monitored by an on-line quadrupole mass spectrometer. The mass spectrometer signals were calibrated before each experiment by using a calibration gas with known composition. All gas-phase components were calibrated except water, which was calculated based on the mass balance. Blank experiments using an inert quartz at identical conditions indicated low contribution of gasphase reactions ( $<2 \%$ methane conversion of gas-phase reaction) in the present work. The accumulated amount of oxygen removal in the reduction step, total oxygen consumption, oxygen consumption to carbon oxidation were estimated based on mass balance on carbon and oxygen using $\mathrm{Ar}$ as the internal stand, which were closed to within $\pm 5 \%$ in all experiments.

The methane conversion (Eq. (1)) and the CO selectivity (Eq. (2)) as well as the hydrogen (Eq. (3)), carbon balances (Eq. (4)) and oxygen vacancy concentration (Eq. (5)) were calculated according to the following equations:

$X_{\mathrm{CH}_{4}}=\frac{N_{\mathrm{CH}_{4}^{\text {in }}}-N_{\mathrm{CH}_{4}^{\text {out }}}}{N_{\mathrm{CH}_{4}^{\text {in }}}} \times 100 \%$

$S_{\mathrm{CO}}=\frac{N_{\mathrm{CO}^{\text {out }}}}{N_{\mathrm{CO}^{\text {out }}}+N_{\mathrm{CO}_{2}^{\text {out }}}} \times 100 \%$

$4 N_{\mathrm{CH}_{4}^{\text {in }}}=4 N_{\mathrm{CH}_{4}^{\text {out }}}+2 N_{\mathrm{H}_{2}^{\text {out }}}+2 \mathrm{~N}_{\mathrm{H}_{2} \mathrm{O}^{\text {out }}}$

$N_{\mathrm{CH}_{4}^{\text {in }}}=N_{\mathrm{CH}_{4}^{\text {out }}}+N_{\mathrm{CO}^{\text {out }}}+N_{\mathrm{CO}}$ out $+N_{C^{\text {out }}}$

Oxygen vacancy concentration $=\frac{N_{\mathrm{CO}^{\text {out }}}+2 \mathrm{~N}_{\mathrm{CO}_{2}^{\text {out }}}+N_{\mathrm{H}_{2} \mathrm{O}^{\text {out }}}}{n}$

where $X_{\mathrm{CH}_{4}}$ is the methane conversion, $\mathrm{S}_{\mathrm{CO}}$ is CO selectivity, $N_{i}$ is mole of compound $i$ within $t(\mathrm{mmol})$, and $n$ is the mole of oxygen carrier.

\section{Results and discussion}

\subsection{Materials characterization}

The XRD spectrum in Fig. 1 shows single-phase perovskite with orthorhombic structure for fresh $\mathrm{LaFeO}_{3}$ (JCPDS Card nos. 371493). The uniform nanostructured textural background with pseudo-spherical particles of average sizes of $170 \mathrm{~nm}$ was observed in SEM and TEM images, where aggregation of individual nanoparticles is occurred (Fig. S1A-B). The size distribution profile in Fig. S1C, represents typical particles between 10 and $1000 \mu \mathrm{m}$. The result of $\mathrm{O}_{2}-\mathrm{TPD}$ indicates that the $\mathrm{LaFeO}_{3}$ perovskite does not have an obvious tendency to release gaseous oxygen with oxygen uncoupling (Fig. S1D). A small amount of $\mathrm{Fe}^{4+}$ in the perovskite can be reduced to $\mathrm{Fe}^{3+}(\sim 0.054 \mathrm{mmol} / \mathrm{g})$ at low temperature 


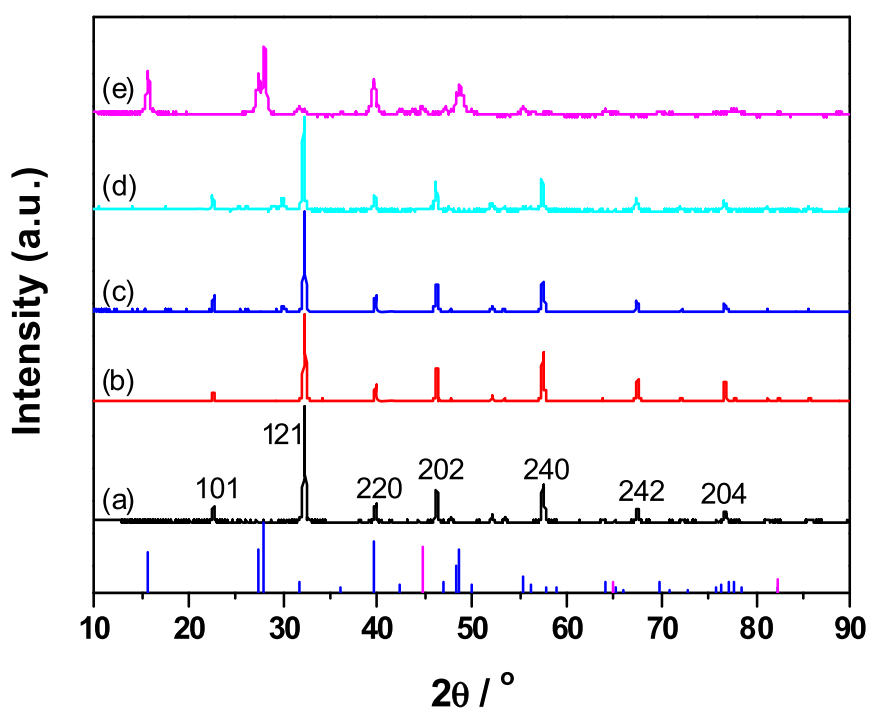

Fig. 1. X-ray diffraction patterns of (a) fresh $\mathrm{LaFeO}_{3}$, (b) after $\mathrm{H}_{2}-\mathrm{TPR}$ to $1173 \mathrm{~K}$, (c) after TPSR from room temperature to $1073 \mathrm{~K}$, (d) to $1145 \mathrm{~K}$ and (e) to $1173 \mathrm{~K}$ (JCPDS 37-1493 for perovskite $\mathrm{LaFeO}_{3}$; JCPDS 36-1481, blue bar for $\mathrm{La}(\mathrm{OH})_{3}$; JCPDS 06-0696, purple bar for metallic Fe).

( $\sim 680 \mathrm{~K}$ ) in $\mathrm{H}_{2}$-TPR (Fig. S1D) (Ciambelli et al., 2001; Chen et al., 2013), which can be further reduced into $\mathrm{Fe}^{2+}(0.185 \mathrm{mmol} / \mathrm{g})$, declaring a limited reducibility of $\mathrm{Fe}^{3+}$ ions in perovskite structure, further confirmed by XRD characterization due to the absence of new phase (Fig. 1). For the peak within low temperature $(\sim 680 \mathrm{~K})$, although there are controversies about the reduction of $\mathrm{Fe}^{4+}$ or the iron species on the surface and the removal of surface oxygen (Ciambelli et al., 2001; Chen et al., 2013; Velichkova et al., 2013), the nonstoichiometric composition contains oxygen vacancies that can be filled up is the only reason for the presence of $\mathrm{Fe}^{4+}$ in order to electrically balance, verified the essentially uniformity about the attribution of the peak within low temperature. The chemical formula is deduced as $\mathrm{LaFe}_{0.013}^{4+} \mathrm{Fe}_{0.987}^{3+} \mathrm{O}_{3.0065}$ according to the $\mathrm{H}_{2}-\mathrm{TPR}$.

In order to decide the relationship between the structure and available oxygen, the combination of $\mathrm{CH}_{4}$-TPSR, XRD and XPS characterization was used to explore the losses of oxygen species, catalyst structure and surface state. In $\mathrm{CH}_{4}$-TPSR, the main products are $\mathrm{CO}$ and $\mathrm{H}_{2}$, while only small amounts of $\mathrm{CO}_{2}$ and $\mathrm{H}_{2} \mathrm{O}$ are detected in Fig. 2. As the temperature higher than $1000 \mathrm{~K}$, more $\mathrm{CH}_{4}$ is converted to $\mathrm{CO}$ and $\mathrm{H}_{2}$. The $\mathrm{CO}$ intensity reaches its peak at $1145 \mathrm{~K}$, then gradually decline; however, the $\mathrm{H}_{2}$ intensity does not drop with $\mathrm{CO}$ intensity, suggesting that carbon deposition occurs on the $\mathrm{LaFeO}_{3}$ surface (Dai et al., 2006b). According to XRD, the perovskite structure is still maintained until to $1140 \mathrm{~K}$ (Fig. 1). However, when the temperature is further increased to $1173 \mathrm{~K}$, new characteristic peaks for $\mathrm{La}(\mathrm{OH})_{3}$, trace $\mathrm{La}_{2} \mathrm{O}_{3}$ and metallic $\mathrm{Fe}$ will present, indicating structure collapse of perovskite. Although the metallic $\mathrm{Fe}$ can be oxidized to $\mathrm{Fe}_{2} \mathrm{O}_{3}$ during cyclic oxidationreduction process, the selectivity of $\mathrm{CO}$ will be poor (Monazam et al., 2013; Piekiel et al., 2012; Cabello et al., 2014b; Bhavsar et al., 2014). Assuming that one monolayer of oxygen amounts to $4 \mu$ $\mathrm{mol} / \mathrm{m}^{2}$ (Kaliaguine et al., 2001), the calculated number of $\mathrm{O}$ atoms is about $264 \mu \mathrm{mol} / \mathrm{m}^{2}$ involving in CLMR process before carbon deposit occurs, which is corresponding to 66 monolayers. We also use XPS to explore the surface state during $\mathrm{CH}_{4}$-TPSR (Fig. 3). The position and shape of La3d peaks agree well with the presence of La (III) compounds: the well evident shake-up contributions at $\sim 833.7 \mathrm{eV}$ and $\sim 850.6 \mathrm{eV}$. No significant differences are observed in the $\mathrm{La}_{3} \mathrm{~d}_{5 / 2}$ doublets $\left(\mathrm{La}_{2} \mathrm{O}_{3}\right.$ at $838.4 \mathrm{eV}$ and $\mathrm{La}(\mathrm{OH})_{3}$ at $833.9 \mathrm{eV}$ ). The high-solution XPS of Fe2p exhibits two peaks at

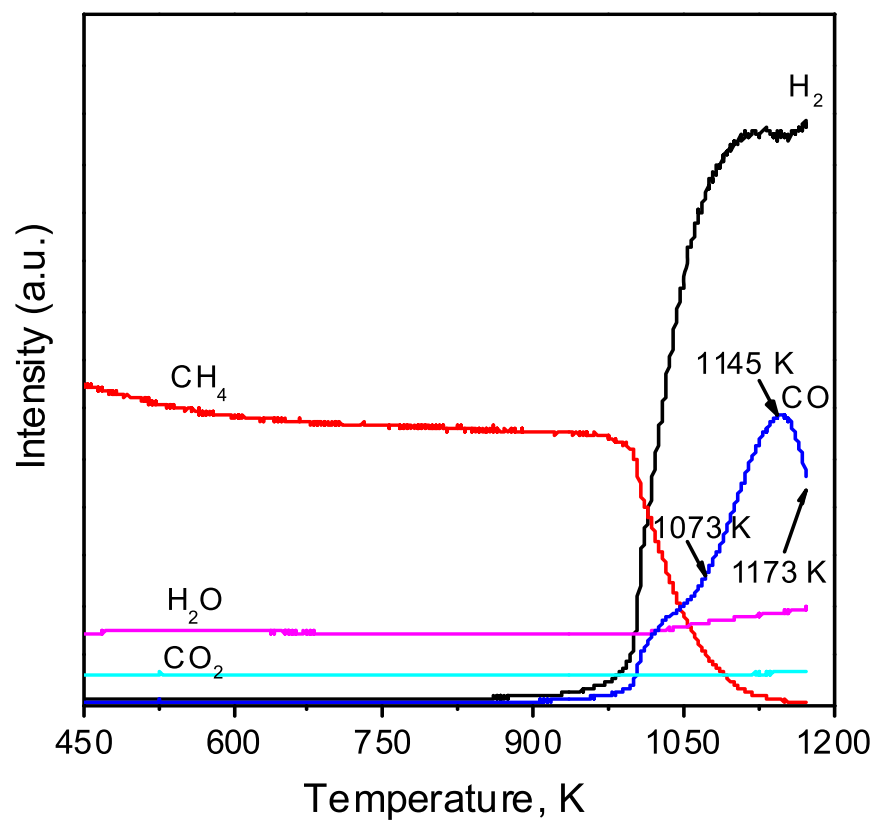

Fig. 2. $\mathrm{CH}_{4}-\mathrm{TPSR}$ over $\mathrm{LaFeO}_{3}$-perovskite oxygen carrier.

710.1 and $723.7 \mathrm{eV}$, which correspond to the peaks of $\mathrm{Fe} 2 \mathrm{p}_{3 / 2}$ and $\mathrm{Fe} 2 \mathrm{p}_{1 / 2}$ in fresh $\mathrm{LaFeO}_{3}$, respectively. After exposing to methane, $\mathrm{Fe}_{2} \mathrm{p}_{3 / 2}$ peak widens and shake-up satellite decreases, which indicates that surface $\mathrm{Fe}^{3+}$ species gain electron and gradually reduce to $\mathrm{Fe}^{2+}$ with methane (Gao et al., 2013). The O1s XPS peaks at 529.0 is attributed to lattice oxygen in perovskite oxide (metaloxygen bond), while 531.1 and $532.4 \mathrm{eV}$ are assigned to weakly bound oxygen on the surface $\left(\mathrm{O}_{2}\right.$ species that are molecularly adsorbed in the subsurface regions of oxygen-deficient perovskitetype compounds) or/and to the surface hydroxyls (Jirátová et al., 2009).

According to $\mathrm{CH}_{4}-\mathrm{TPSR}, \mathrm{XRD}$ and XPS characterization, the maximum amount of oxygen that can release without structure collapse, namely the capacity of reversible oxygen storage, is found to be about $0.39 \mathrm{~mol} / \mathrm{mol}$ oxygen carriers. The stoichiometric reaction between $\mathrm{CH}_{4}$ and oxygen carrier can be expressed as follows:

$\mathrm{LaFeO}_{3}+0.39 \mathrm{CH}_{4} \rightarrow \mathrm{LaFeO}_{2.61}+0.39 \mathrm{CO}+0.78 \mathrm{H}_{2}$

The reaction represents only selective oxidation, and ignores complete oxidation to $\mathrm{CO}_{2}$ and $\mathrm{H}_{2} \mathrm{O}$, because the amount for complete oxidation is much smaller than that for selective oxidation. Thus, the neglect of the complete oxidation in Eq. (6) will not lead to significant errors.

The solid conversion of perovskite-oxide $\mathrm{LaFeO}_{3}$ oxide $\left(\alpha_{(t)}\right)$ is calculated as:

$\alpha_{(t)}=\frac{N_{C H_{4}, 0} \cdot X_{C_{H}}}{0.39 \cdot \frac{w_{p}}{M_{p}}}$

where $N_{C H 4,0}$ is the mole of methane injected into the reactor for a certain time $(t), X_{C H 4}$ is the conversion of methane, $w_{p}$ is the mass of $\mathrm{LaFeO}_{3}$ perovskite loaded into the reactor, and $M_{p}$ is the molecular weight of $\mathrm{LaFeO}_{3}$ perovskite.

\subsection{Reactivity and stability toward CLMR}

\subsubsection{Effect of reduction parameters on oxygen carrier conversion}

Fig. 4A shows the effect of the gas to solid molar ratio on the oxygen carrier conversion $(\alpha)$, indicating sigmoidal shapes for all curves. High gas to solid molar ratio is necessary to increase the 

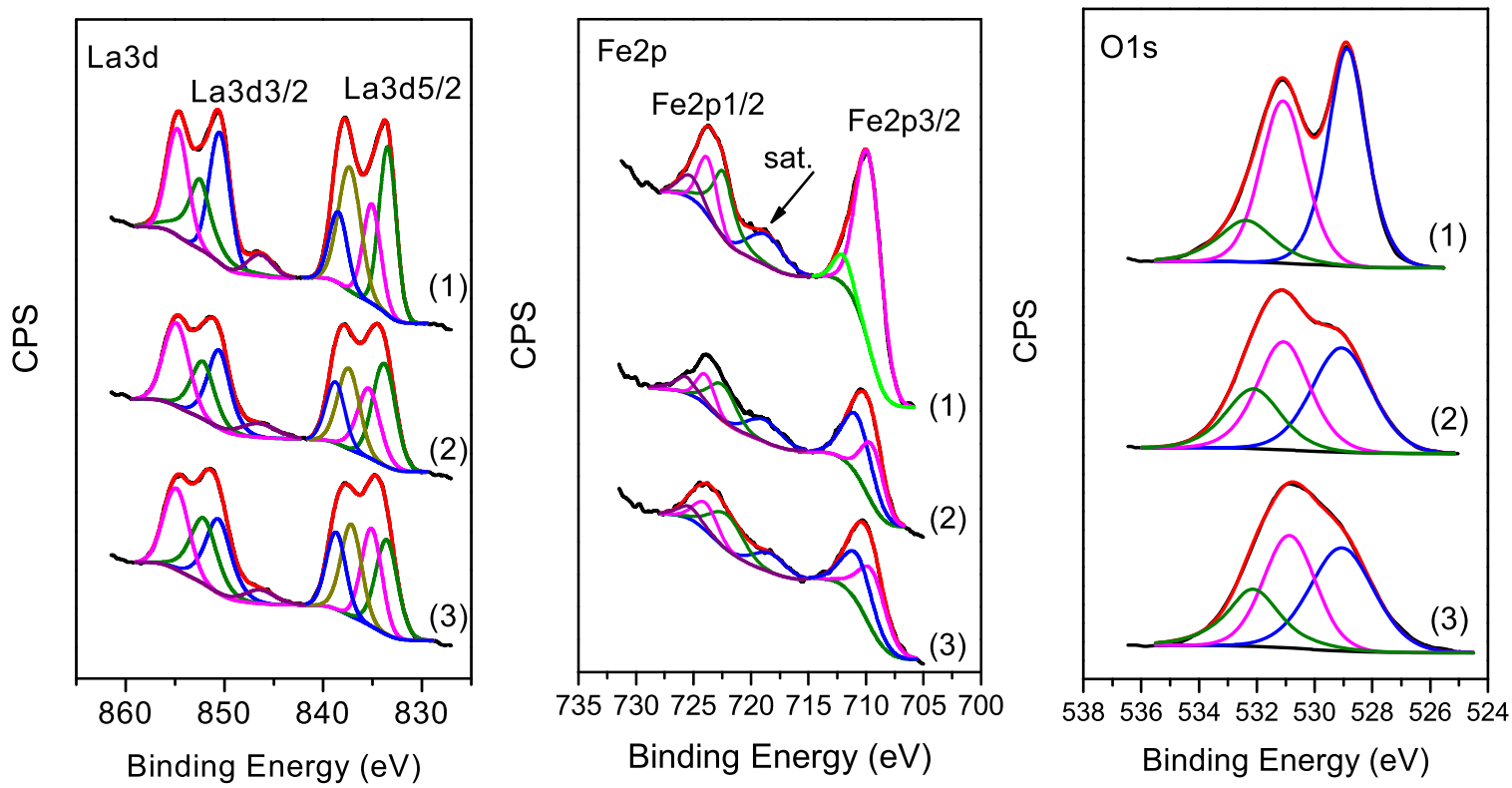

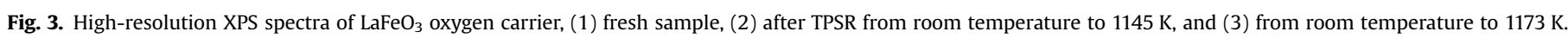
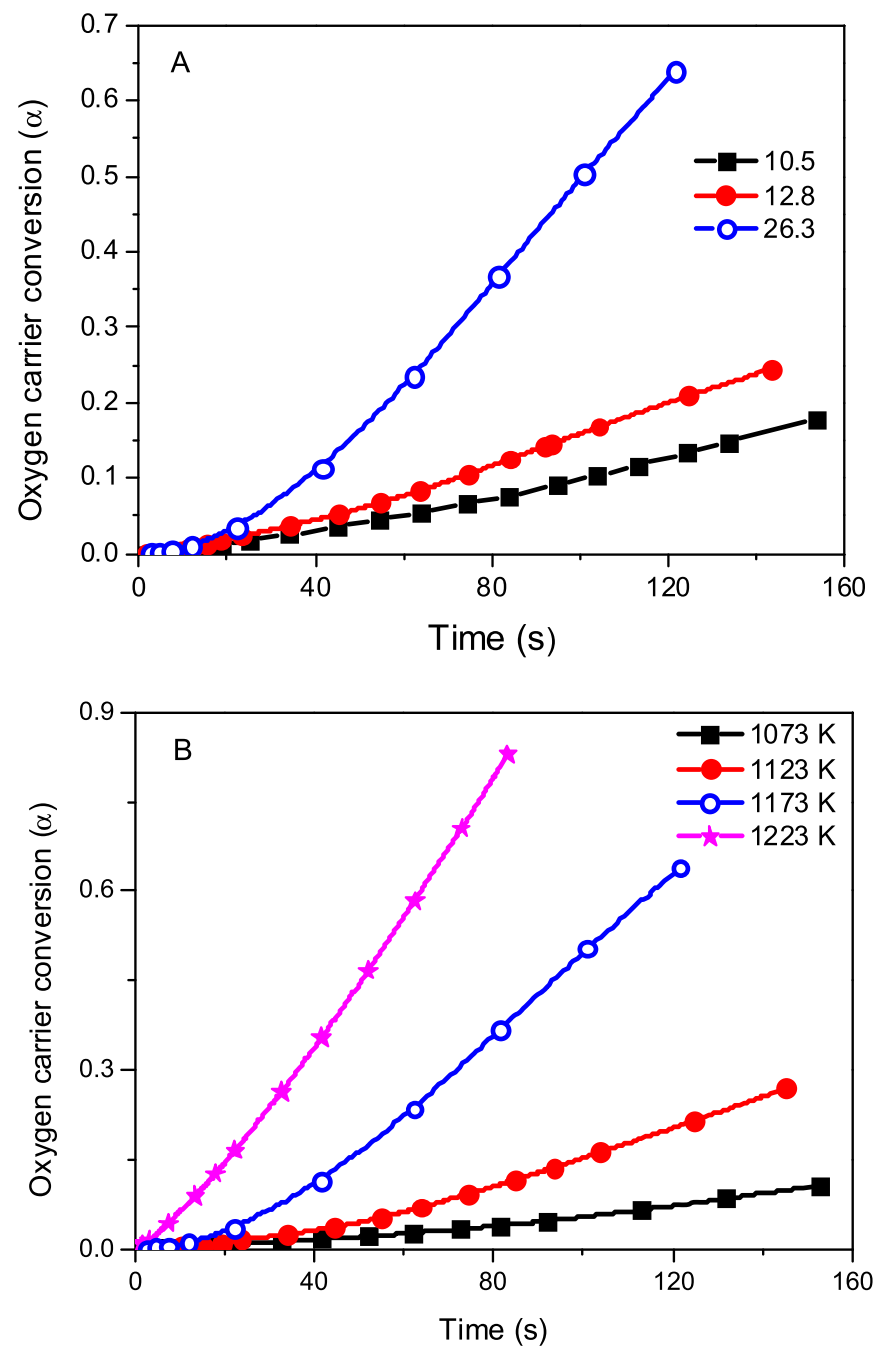

Fig. 4. Oxygen carrier conversion vs. time for (A) varying gas to solid molar ratios at $1173 \mathrm{~K}$ and $(\mathrm{B})$ reaction temperatures with gas to solid ratio of 26.3 . oxygen carrier conversion at short reduction time, which has been observed in our previous work (Dai et al., 2012). The reduction rate of $\mathrm{LaFeO}_{3}$ oxygen carrier is accelerated with the reaction time, and the trend is more dominant at high gas to solid molar ratio, which is clearly different from the two-stage reduction process over $\mathrm{Ni}$ based oxygen carriers, characterized by the fast $\mathrm{NiO}$ reduction and low nickel aluminate reactivity (Dueso et al., 2012). The oxygen carrier conversion $(\alpha)$ for the various temperatures under gas to solid molar ratio of 26.3 is presented in Fig. 4B. The oxygen carrier conversion $(\alpha)$ slowly increases with reaction time at 1073 and $1123 \mathrm{~K}$, whereas it sharply increases at the reaction temperature of 1173 and $1223 \mathrm{~K}$. The sigmoidal shapes may be divided into two distinct regions. In the first region, the conversion of $\mathrm{LaFeO}_{3}$ oxygen carrier is slowly increased due to the presence of an induction period $(0<\alpha<0.10)$. The length of induction period is temperature dependent, which becomes longer at lower temperature (Liu et al., 2001). The dissociation of $\mathrm{CH}_{4}$ and reaction rate is accelerated with the active centers increased in the second region. The acceleration $(\alpha>0.10)$ is more dramatic under high temperature, suggesting more available oxygen species at high temperature for the same reduction time. In this work, we don't observe the deceleration or decay period, because the reduction time is controllable to avoid the carbon deposit and structure collapse of oxygen carrier.

3.2.2. Stability test by sequential reduction-oxidation (redox) cycles

Fig. 5 depicts the responses of reactants and products during the redox reaction between $\mathrm{O}_{2} / \mathrm{Ar}$ oxidation for $10 \mathrm{~s}$ and $\mathrm{CH}_{4} / \mathrm{He}$ reduction for $30 \mathrm{~s}$ over the $\mathrm{LaFeO}_{3}$ oxygen carrier at $1173 \mathrm{~K}$. Only a small amount of methane is oxidized to $\mathrm{CO}_{2}$ at the first cycle, and then $\mathrm{CO}$ and $\mathrm{H}_{2}$ are dominant products, which further verifies the feasibility in Eq. (6). The $\mathrm{H}_{2} / \mathrm{CO}$ ratio is about 1.95 and close to the stoichiometric ratio of the POM. The CO selectivity keeps more than $96 \%$. The oxygen species consumed at reductive atmospheres $\left(\mathrm{CH}_{4} / \mathrm{He}\right)$ can be replenished at oxidative atmospheres for a short time (10 s). The oxygen carrier conversion $(\alpha)$ remains at a level of $\sim 6 \%$ during the whole redox experiment. It seems that $\mathrm{LaFeO}_{3}$ oxygen carrier display a higher stability under CLMR conditions (Figs. S2 and S3), suggesting that the available oxygen over each successive reduction step is essentially not affected by the number of oxidation-reduction cycles. 
Time (s)

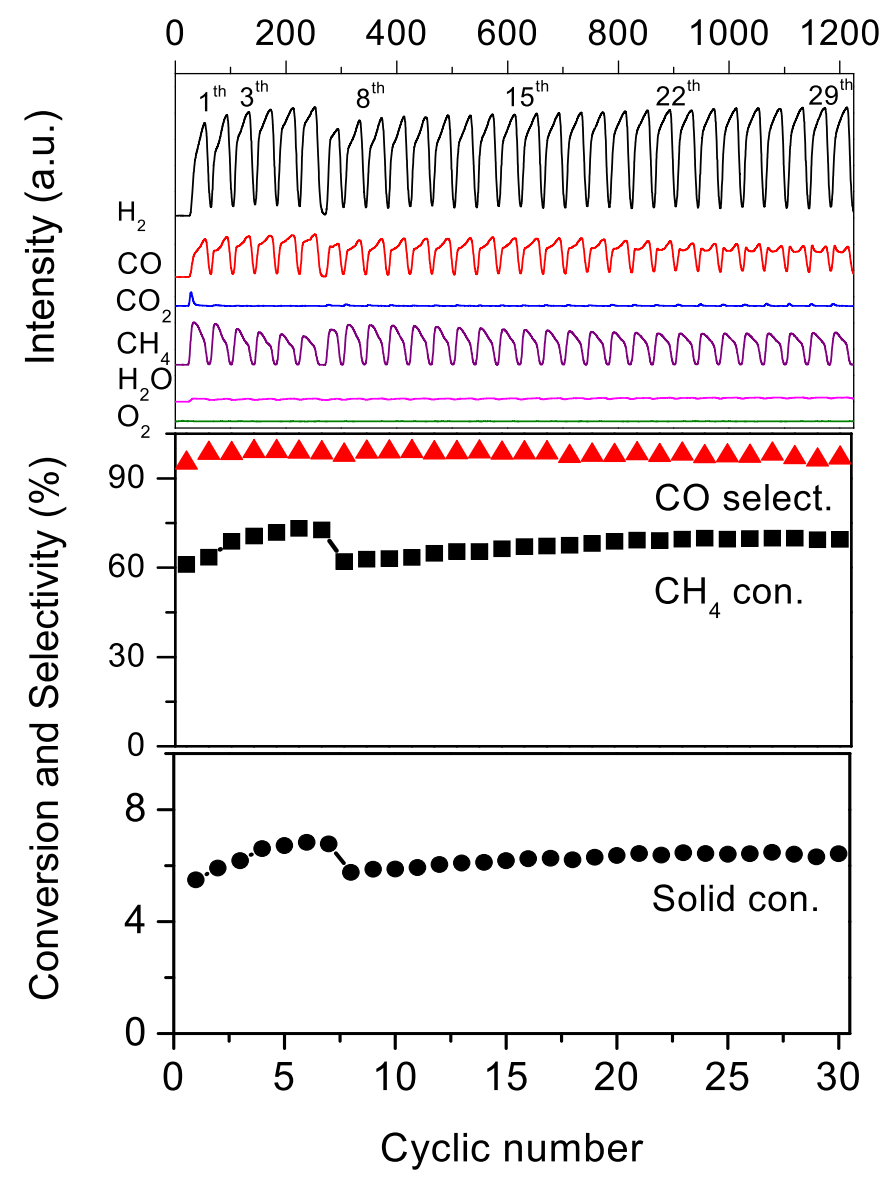

Fig. 5. Sequential redox reaction to simulate chemical-looping methane reforming process over $\mathrm{LaFeO}_{3}$ oxygen carrier at $1173 \mathrm{~K}$.

Table 1

Parameters used to evaluate effects of diffusion limitations at $1173 \mathrm{~K}$.

\begin{tabular}{llll}
\hline $\begin{array}{l}\text { Parameters used to evaluate effects of } \\
\text { external diffusion limitations }\end{array}$ & $\begin{array}{l}\text { Parameters used to evaluate effects of } \\
\text { internal diffusion limitations }\end{array}$ \\
\hline $\mathrm{D}(\mu \mathrm{m})$ & 1000 & $\mathrm{D}(\mu \mathrm{m})$ & 1000 \\
$w_{p}(\mathrm{~g})$ & 0.25 & $w_{p}(\mathrm{~g})$ & 0.25 \\
$\mathrm{D}_{\mathrm{AB}}\left(\mathrm{m}^{2} / \mathrm{s}\right)$ & $2.241 \times 10^{-4}$ & $-r_{\mathrm{CH} 4 \mathrm{r}}(\mathrm{mol} / \mathrm{g} \mathrm{s})$ & $8.31 \times 10^{-6}$ \\
$C_{\mathrm{CH} 4 \mathrm{~b}}\left(\mathrm{~mol} / \mathrm{m}^{3}\right)$ & 4.496 & $\rho$ & 1350 \\
$C_{\mathrm{CH} 4 \mathrm{~s}}\left(\mathrm{~mol} / \mathrm{m}^{3}\right)$ & 0 & $\mathrm{D}_{\text {eff }}\left(\mathrm{m}^{2} / \mathrm{s}\right)$ & $2.241 \times 10^{-5}$ \\
$W_{\mathrm{CH} 4 \mathrm{r}}\left(\mathrm{mol} / \mathrm{m}^{2} \mathrm{~s}\right)$ & 2.015 & $C_{\mathrm{CH} 4 \mathrm{~b}}\left(\mathrm{~mol} / \mathrm{m}^{3}\right)$ & 4.496 \\
$-r_{\mathrm{CH} 4 \mathrm{robs}}\left(\mathrm{mol} / \mathrm{m}^{2} \mathrm{~s}\right)$ & $1.37 \times 10^{-6}$ & $C_{\mathrm{WP}}$ & $2.784 \times 10^{-5}$ \\
\hline
\end{tabular}

Table 2

Commonly kinetic models for gas-solid reaction.

\begin{tabular}{clll}
\hline Kinetic model & $\begin{array}{l}\text { Kinetic } \\
\text { mechanism }\end{array}$ & $\begin{array}{l}\text { Differential forms } \\
\left(f(\alpha)=\frac{1}{k} \frac{d \alpha}{d t}\right)\end{array}$ & $\begin{array}{l}\text { Integrated forms } \\
(g(\alpha)=k t)\end{array}$ \\
\hline $\begin{array}{c}\text { Kinetic-order } \\
\text { models }\end{array}$ & $\begin{array}{l}\text { 1st order } \\
\text { 2nd order }\end{array}$ & $\begin{array}{l}1-\alpha \\
(1-\alpha)^{2}\end{array}$ & $\begin{array}{l}-\ln (1-\alpha) \\
(1-\alpha)^{-1}-1\end{array}$ \\
$\begin{array}{c}\text { Shrinking } \\
\text { core model }\end{array}$ & 2-D & $2(1-\alpha)^{1 / 2}$ & $1-(1-\alpha)^{1 / 2}$ \\
& $3(1-\alpha)^{2 / 3}$ & $1-(1-\alpha)^{1 / 3}$ \\
Nucleation & 2-D & $2(1-\alpha)[\ln (1-\alpha)]^{1 / 2}$ & {$[-\ln (1-\alpha)]^{1 / 2}$} \\
model & 3-D & $3(1-\alpha)[\ln (1-\alpha)]^{2 / 3}$ & {$[-\ln (1-\alpha)]^{2 / 3}$} \\
\hline
\end{tabular}

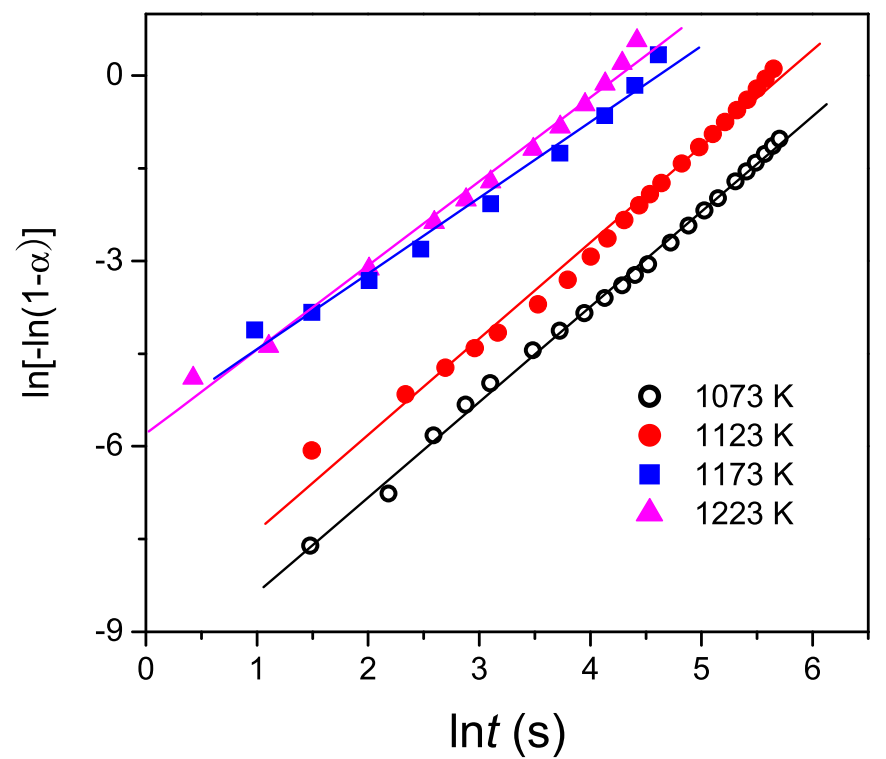

Fig. 6. Plots obtained for varying different temperature following the Hancock and Sharp method $\left(R^{2}>0.98\right)$.

\subsection{Kinetic model}

\subsubsection{Rate-limited step}

Heterogeneous process generally involves three stages: external mass transport (reactant diffusion to surface), chemical reaction and internal mass transport (reactant diffusion to bulk). During kinetic determination, external and internal diffusion should be avoided, which could limit the chemical reaction rate. Frossling correlation and Weisz-Prater criterion can be used to assess them, respectively (Sedor et al., 2008; Piekiel et al., 2012).

For external diffusion limitation and negligible shear stress, the radial flux of methane $\left(W_{\mathrm{CH} 4 \mathrm{r}}, \mathrm{mol} / \mathrm{m}^{2} \mathrm{~s}\right)$ can be calculated on the basis of the Sherwood number with Frossling's dimensionless correlation, which then compares with the observed reduction rate $\left(-r_{\mathrm{CH} 4 \mathrm{robs}}, \mathrm{mol} / \mathrm{m}^{2} \mathrm{~s}\right)$. The $W_{\mathrm{CH} 4 \mathrm{r}}$ and $-r_{\mathrm{CH} 4 \text { robs }}$ can be expressed as follows.

$$
\begin{aligned}
& W_{\mathrm{CH}_{4} \mathrm{r}}=\frac{2 D_{A B}}{D}\left(C_{\mathrm{CH}_{4} b}-C_{\mathrm{CH}_{4} \mathrm{~s}}\right) \\
& -r_{\mathrm{CH}_{4} \mathrm{obs}}=\frac{N_{\mathrm{CH}_{4} \mathrm{O}}}{w \cdot S_{e x}} \frac{d X_{P}}{d t}
\end{aligned}
$$

The diffusivity of methane in $\operatorname{argon}\left(D_{\mathrm{AB}}\right)$ inside the reactor at different temperature and atmospheric pressure was calculated using the Fuller, Schettler and Giddings method (Sedor et al., 2008), and was shown in Table 1 and Table S1. $D_{\mathrm{AB}}$ at $1173 \mathrm{~K}$ was calculated as $2.241 \times 10^{-4} \mathrm{~m}^{2} / \mathrm{s}$. The $-r_{\mathrm{CH} 4 \text { robs }}$ was calculated on the basis of the oxygen carrier conversion, external surface area of the carrier, and the number of moles of methane injected during a certain time $(t)$.

For internal diffusion limitation, the Weisz-Prater can be expressed as follows.

$C_{\mathrm{WP}}=\frac{-r_{C H_{4} o b s}^{\prime} \cdot \rho \cdot(D / 2)^{2}}{D_{e f f} \cdot C_{C_{4} b}}$

where the effective diffusivity $\left(D_{\text {eff }}\right)$ is estimated as $0.1 D_{\mathrm{AB}}$ (Hardiman et al., 2006), and $\rho$ is the density of the $\mathrm{LaFeO}_{3}$ oxygen carrier.

The all parameters that are used to evaluate the presence of diffusion limitations were listed in Table 1 . The results indicate that the observed reaction rate is much smaller than the radial flux 

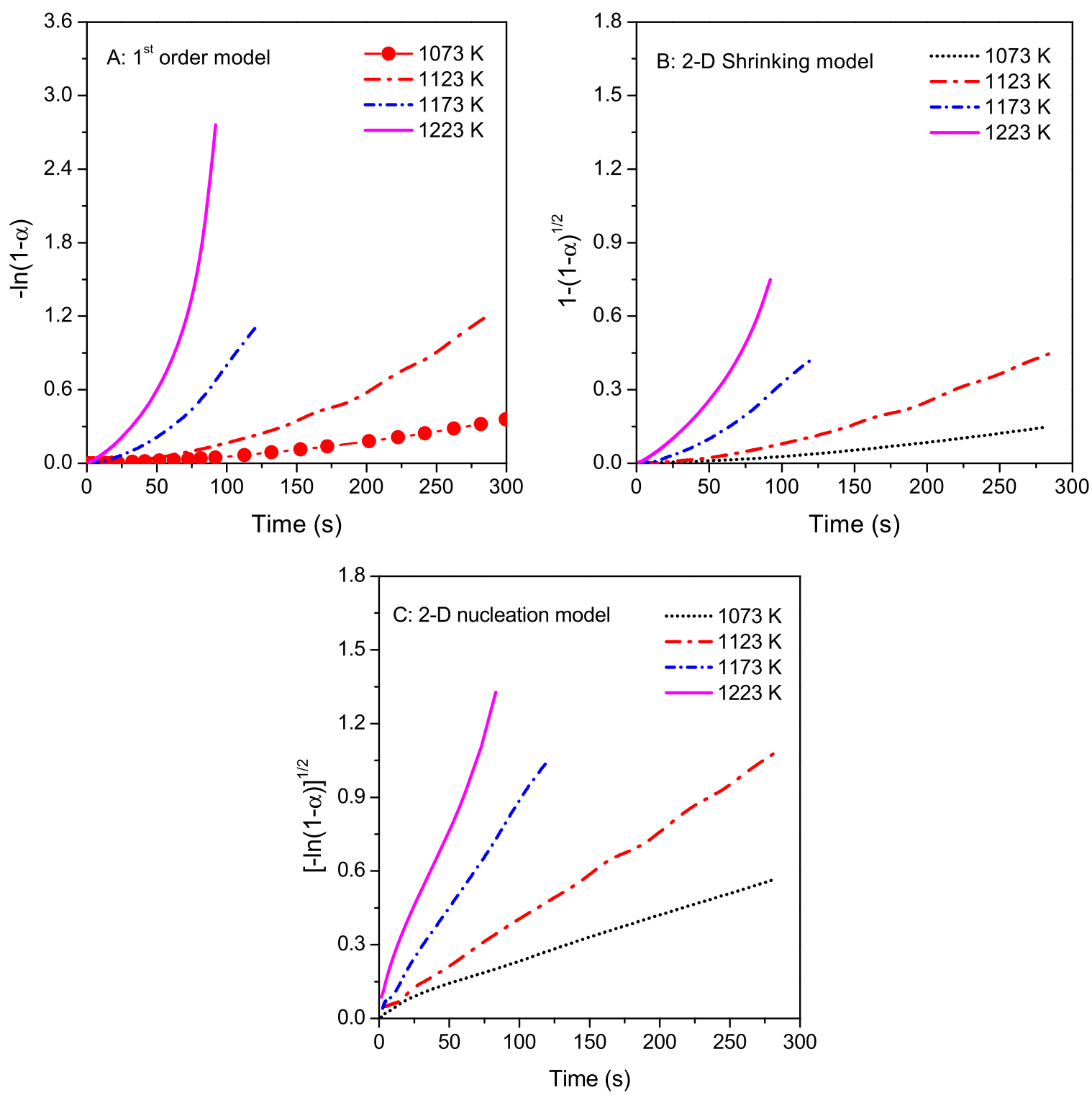

Fig. 7. Plots obtained based on application of different gas-solid models.

of methane ( $W_{\mathrm{CH} 4 \mathrm{r}} \ll \mathrm{r}_{\mathrm{CH} 4 \mathrm{obs}}$ ), while the Weisz-Prater parameter is much smaller than $1\left(C_{\mathrm{WP}}=2.784 \times 10^{-5}\right)$, which suggests that external and internal diffusion of methane are not limiting the rate of the overall reduction reaction.

\subsubsection{Kinetic model}

Reduction kinetics of oxygen carrier is generally used for the design of reactor, which is traditionally expected to describe the process in terms of the reaction model and of the Arrhenius parameters. Generally, an overall reaction rate is a function of solid material conversion $(\alpha)$, the gas-phase composition at constant feed flow rate, methane partial pressure and differential conversion (Piekiel et al., 2012):

$\frac{d \alpha}{d t}=k(T) \cdot f(\alpha)$

The rate constant $(k(T))$ is usually assumed to obey the Arrhenius equation:

$k(T)=A \cdot \exp \left(\frac{-E_{a}}{R T}\right)$ where $\alpha$ is the oxygen carrier conversion, $t$ is the reduction time (s), $T$ is the absolute temperature $(\mathrm{K}), f(\alpha)$ is a function that represents the reaction mechanism, $R$ is the gas constant, $A$ and Ea are the pre-exponential factor and the activation energy, respectively. For reaction kinetics under isothermal conditions, analytically integrated to yield:

$g(\alpha)=\int_{0}^{\alpha} \frac{d \alpha}{f(\alpha)}=k(T) \cdot t$

where $g(\alpha)$ is the integral form of the reaction model.

Both empirical and mechanistic models for gas-solid reaction are available in the technical literature, such as power law model, shrinking core model (SCM), nucleation and nuclei growth model (NNGM) (Adanez et al., 2012; Hossain et al., 2008; Luo et al., 2014). As mentioned above, external and internal diffusion of methane are excluded in limiting the rate of the overall reduction reaction. The kinetic-order models, contraction models (chemical reaction control) and nucleation models in Table 2 are determined to fit the reduction of $\mathrm{LaFeO}_{3}$ data with suitable rate expressions derived from gas-solid models. 


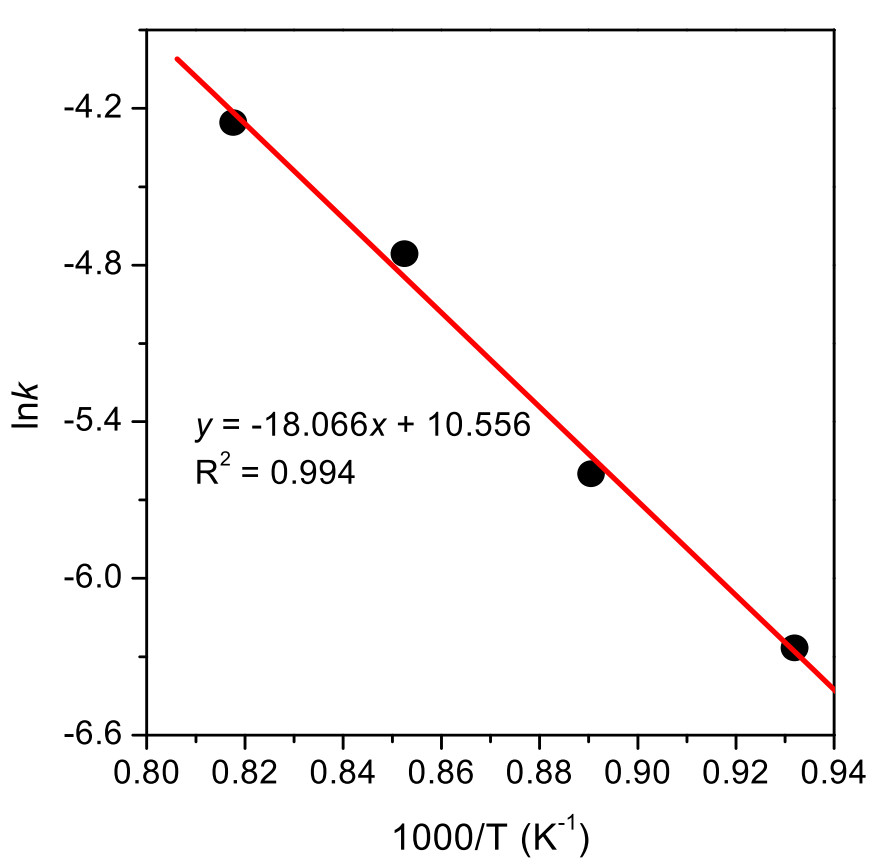

Fig. 8. Arrhenius plot used for evaluation of the activation energy of the reduction process following 2-D nucleation model.

\subsubsection{Model evaluation}

Hancock and Sharp developed a convenient graphical method of comparing this type of experimental data, which can be expressed in the form of the following equation to determine the reaction mechanism (Hancock and Sharp, 1972):

$\ln [-\ln (1-\alpha)]=n \ln t+\ln \beta$

where $\alpha$ is the oxygen carrier conversion, $\beta$ is a constant which is partially dependent upon the nucleation frequency and rate of grain growth, and $n$ is a constant associated with the geometry of the system. Presentation of this data in the specific form of the plots of $\ln [-\ln (1-\alpha)]$ against $\ln t$ are used to identify the reaction mechanism, which depend on the resulted gradient $(n)$. If $n$ is below 1 , the reaction is in favor of a diffusion process, whereas if $1<n<2$, the phase boundary (or interface) control is likely to be dominant. Fig. 6 suggests that the average value of $n$ is close to 1.5, which indicates the mechanism of phase boundary (or interface) control is likely to be dominant.

In order to apply the model-fitting method, at constant reduction temperature (T), Eq. (13) will plot as a straight line for any $g(\alpha)$ regardless of the form of that reaction mechanism $[g(\alpha)]$. The modeling results are presented in Fig. 7 and Figs. S4-6. The kinetic-order models can only be fitted well at low temperature $(1073 \mathrm{~K})$ in Fig. $7 \mathrm{~A}$, indicating that kinetic-order models cannot agree with the experimental data in the whole reductive temperature range. Fig. 7B shows that the contraction model can only fit the experimental data well at low temperatures, but it is not as good as those of the data obtained at higher temperatures of 1173 and $1223 \mathrm{~K}$. Notably, the 2-D nucleation and nuclei growth model is the best suited to model the experimental results $\left(R^{2}>0.99\right)$
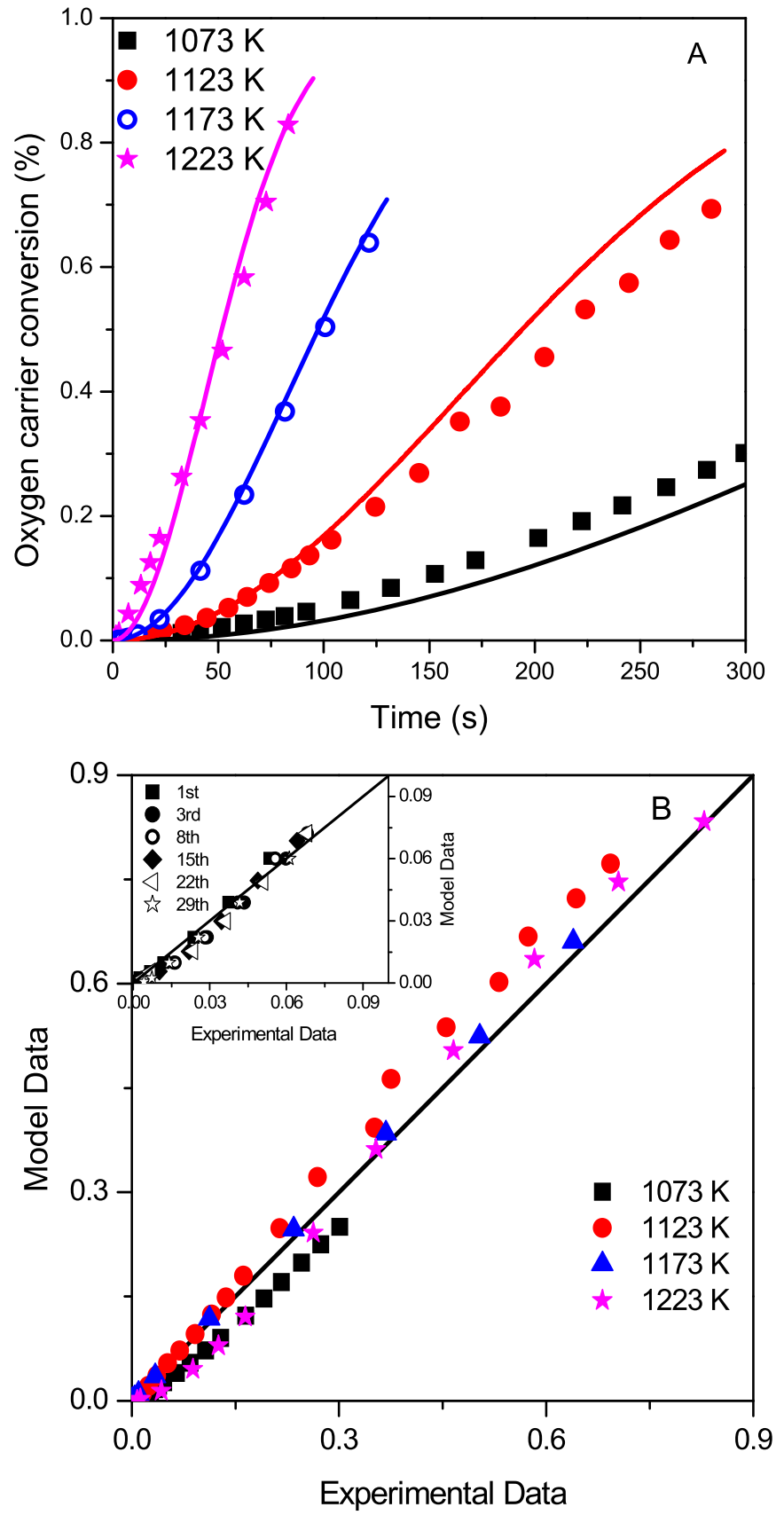

Fig. 9. Comparison of experimental data and fitting by 2-D nucleation model (A), Parity plots for conversion of $\mathrm{LaFeO}_{3}$ oxygen carrier between 2-D nucleation model data and experimental data (B) at $1173 \mathrm{~K}$. Symbols: experimental data. Short dot lines: model predictions from 2-D nucleation model.

(Fig. 7C). The values of kinetic rate constant $(k)$ can be determined at different temperatures from the slope obtained by plotting $g(\alpha)$ against time, as shown in Fig. 8. The resulted apparent activation energy $\left(E_{\mathrm{a}}\right)$ is about $151 \mathrm{~kJ} / \mathrm{mol}$, while the pre-exponential factor $(A)$ is approximately $4.53 \times 10^{4} \mathrm{~s}^{-1}$. The obtained activation

Table 3

Activation energy for CLMR reported in the literature together with the proposed 2-D nucleation model.

\begin{tabular}{|c|c|c|c|c|c|}
\hline Oxygen carrier & Temperature range & Experimental method & Model & Ea $(\mathrm{kJ} / \mathrm{mol})$ & Reference \\
\hline $\mathrm{LaFeO}_{3}$ & $1073 \sim 1223 \mathrm{~K}$ & Isothermal MS & 2-D nucleation model & 151 & This work \\
\hline $\mathrm{MnFe}_{2} \mathrm{O}_{4}$ (Jacobsite) & $1073 \sim 1173 \mathrm{~K}$ & Isothermal TGA & Diffusion control & 139 & Go et al., 2008 \\
\hline $\mathrm{CeO}_{2}$ & $873 \sim 1123 \mathrm{~K}$ & Isothermal TCD & - & 137 & Otsuka et al., 1999 \\
\hline $\mathrm{CoWO}_{4}$ & $1123 \sim 1223 \mathrm{~K}$ & Isothermal TGA & 1 st order reaction & 221 & Castillo et al., 2013 \\
\hline
\end{tabular}


energy is compared with those of other studies for CLMR as shown in Table 3. The activation energy over $\mathrm{LaFeO}_{3}$ oxygen carrier has similar value of activation energy with $\mathrm{CeO}_{2}$ and $\mathrm{MnFe}_{2} \mathrm{O}_{4}$, and is lower than that of $\mathrm{CoWO}_{4}$ (Otsuka et al., 1999; Go et al., 2008; Castillo et al., 2013).

\subsubsection{Model validity}

The validity of 2-D nucleation model for CLMR to syngas has been verified in Fig. 9A. It can be seen that the simulated values of oxygen conversion as a function of time are in good agreement with the experimental values, although there are some deviation the deviation from the experimental data for 1073 and $1123 \mathrm{~K}$ at long reaction time $(t>150 \mathrm{~s})$. Root mean squared error (RMSE) and determination coefficient $\left(R^{2}\right)$ are also calculated as statistical indicators to examine the adequacy of the 2-D nucleation model. The 0.0346 and 0.91 for RMSE and $R^{2}$, respectively, also confirm a good fit for the experimental data. Furthermore, the obtained results of different cyclic number $(\alpha<0.10)$ by sequential redox reaction also verify the validity as the inset in Fig. 9B, which also show statistical indicators of 0.00399 and 0.97 for RMSE and $R^{2}$, respectively. Therefore, the $2-\mathrm{D}$ nucleation model is reasonable and reliable for CLMR to syngas. The current kinetics study by 2-D nucleation model provides a simplified approach which will help in interpreting the relationship of oxygen carrier conversion vs. time for a gas-solid reaction over fuel reactor by CLMR using $\mathrm{LaFeO}_{3}$ as oxygen carrier, and is expected to help in the prediction, design and optimization purposes of a CLMR system.

\section{Conclusion}

The reduction kinetics of $\mathrm{LaFeO}_{3}$ oxygen carrier by chemicallooping methane reforming to syngas, which characterized sigmoidal shapes, was investigated in the present work. The results from TPR, TPD, XRD SEM, TEM and XPS characterization suggest the stoichiometric relationship between oxygen carrier and methane in chemical-looping process. By applying the Hancock and Sharp method to the data, an average value of $n=1.5$ is obtained, which indicates the phase boundary control is likely to be dominant. A wide variety of gas-solid reaction kinetics models are evaluated to determine the best fit to the experimental data, where the 2-D nucleation and nuclei growth model is used to study the kinetic parameters. The apparent activation energy is found about $151 \mathrm{~kJ} / \mathrm{mol}$, and the pre-exponential factor is about $4.53 \times 10^{4} \mathrm{~s}^{-1}$. Results obtained from this kinetic study indicate that the model performs well with the experimental conversiontime curves for the reduction of $\mathrm{LaFeO}_{3}$ oxygen carrier in CLMR. The validity is also verified by the data from sequential redox cycles to simulate chemical-looping methane reforming process.

\section{Acknowledgments}

The authors acknowledge the financial supports from the NSFC (No. 21576288).

\section{Appendix A. Supporting information}

Supplementary data associated with this article can be found in the online version at http://dx.doi.org/10.1016/j.ces.2016.07.011.

\section{References}

Adanez, J., Abad, A., Labiano, F.G., Gayan, P., de Diego, L.F., 2012. Progress in chemical-looping combustion and reforming technologies. Prog. Energ. Combust.
38, 215-282.

Bhavsar, S., Veser, G., 2013. Bimetallic Fe-Ni oxygen carriers for chemical looping combustion. Ind. Eng. Chem. Res. 52, 15342-15352.

Bhavsar, S., Tackett, B., Veser, G., 2014. Evaluation of iron- and manganese-based mono- and mixed-metallic oxygen carriers for chemical looping combustion. Fuel 136, 268-279.

Cabello, A., Gayán, P., García-Labiano, F., de Diego, L.F., Abad, A., Izquierdo, M.T., Adánez, J., 2014a. Relevance of the catalytic activity on the performance of a $\mathrm{NiO} / \mathrm{CaAl}_{2} \mathrm{O} 4$ oxygen carrier in a CLC process. Appl. Catal. B 147, 980-987.

Cabello, A., Dueso, C., García-Labiano, F., Gayán, P., Abad, A., de Diego, L.F., Adánez J., 2014b. Performance of a highly reactive impregnated $\mathrm{Fe}_{2} \mathrm{O}_{3} / \mathrm{Al}_{2} \mathrm{O}_{3}$ oxygen carrier with $\mathrm{CH}_{4}$ and $\mathrm{H}_{2} \mathrm{~S}$ in a 500 Wth CLC unit. Fuel 121, 117-125.

Castillo, T., de los, R., Gutiérrez, J.S., Ortiz, A.L., Collins-Martínez, V., 2013. Global kinetic evaluation during the reduction of $\mathrm{CoWO}_{4}$ with methane for the production of hydrogen. Int. J. Hydrog. Energy 38, 12519-12526.

Chen, J.H., Shen, M.Q., Wang, X.Q., Wang, J., Su, Y.G., Zhao, Z., 2013. Catalytic performance of $\mathrm{NO}$ oxidation over $\mathrm{LaMeO}_{3}(\mathrm{Me}=\mathrm{Mn}, \mathrm{Fe}, \mathrm{Co})$ perovskite prepared by the sol-gel method. Catal. Commun. 37, 105-108.

Chen, Y.G., Galinsky, N., Wang, Z.R., Li, F.X., 2014. Investigation of perovskite supported composite oxides for chemical looping conversion of syngas. Fuel 134, 521-530.

Choudhary, T.V., Choudhary, V.R., 2008. Energy-efficient syngas production through, catalytic oxy-methane reforming reactions. Angew. Chem. Int. Ed. 47 1828-1847.

Ciambelli, P., Cimino, S., De Rossi, S., Lisi, L., Minelli, G., Porta, P., Russo, G., 2001. $\mathrm{AFeO}_{3}(\mathrm{~A}=\mathrm{La}, \mathrm{Nd}, \mathrm{Sm})$ and $\mathrm{LaFe}_{1-\mathrm{x}} \mathrm{Mg}_{\mathrm{x}} \mathrm{O}_{3}$ perovskites as methane combustion and CO oxidation catalysts: structural, redox and catalytic properties. Appl. Catal. B: Environ. 29, 239-250.

Dai, X.P., Li, R.J., Yu, C.C., Hao, Z.P., 2006a. Unsteady-state direct partial oxidation of methane to synthesis gas in a fixed-bed reactor using $\mathrm{AFeO}_{3}(\mathrm{~A}=\mathrm{La}, \mathrm{Nd}, \mathrm{Eu}$ ) perovskite-type oxides as oxygen storage. J. Phys. Chem. B 110, 22525-22531.

Dai, X.P., Wu, Q., Li, R.J., Yu, C.C., Hao, Z.P., 2006b. Hydrogen production from a combination of the water-gas shift and redox cycle process of methane partial oxidation via lattice oxygen over $\mathrm{LaFeO}_{3}$ perovskite catalyst. J. Phys. Chem. B 110, 25856-25862.

Dai, X.P., Li, J., Fan, J.T., Wei, W.S., Xu, J., 2012. Synthesis gas generation by chemicallooping reforming in a circulating fluidized bed reactor using perovskite $\mathrm{LaFeO}_{3}$-based oxygen carriers. Ind. Eng. Chem. Res. 51, 11072-11082.

de Diego, L.F., Ortiz, M., Adánez, J., Labiano, F.G., Abad, A., Gayán, P., 2008. Synthesis gas generation by chemical-looping reforming in a batch fluidized bed reactor using Ni-based oxygen carriers. Chem. Eng. J. 144, 289-298.

Dueso, C., Ortiz, M., Abad, A., Labiano, F.G., de Diego, L.F., Gayán, P., Adánez, J., 2012. Reduction and oxidation kinetics of nickel-based oxygen-carriers for chemicallooping combustion and chemical-looping reforming. Chem. Eng. J. 188, 142-154.

Enger, B.C., Lødeng, R., Holmen, A., 2008. A review of catalytic partial oxidation o methane to synthesis gas with emphasis on reaction mechanisms over transition metal catalysts. Appl. Catal. A 346, 1-27.

Galinsky, N.L., Shafiefarhood, A., Chen, Y.G., Neal, L., Li, F.X., 2015. Effect of support on redox stability of iron oxide for chemical looping conversion of methane. Appl. Catal. B: Environ. 164, 371-379.

Gao, J.N., Ran, X.Z., Shi, C.M., Cheng, H.M., Cheng, T.M., Su, Y.P., 2013. One-step solvothermal synthesis of highly water-soluble, negatively charged superparamagnetic $\mathrm{Fe}_{3} \mathrm{O}_{4}$ colloidal nanocrystal clusters. Nanoscale 5, 7026-7033.

García, V., Caldes, M.T., Joubert, O., Gautron, E., Mondragón, F., Moreno, A., 2010. Methane oxidation by lattice oxygen of $\mathrm{Ni} / \mathrm{BaTi}_{1-\mathrm{x}} \mathrm{In}_{\mathrm{x}} \mathrm{O}_{3-\delta}$ catalysts. Catal. Today 157, 177-182.

Go, K.S., Son, S.R., Kim, S.D., 2008. Reaction kinetics of reduction and oxidation of metal oxides for hydrogen production. Int. J. Hydrog. Energy 33, 5986-5995.

Hancock, J.D., Sharp, J.H., 1972. Method of comparing solid-state kinetic data and its application to the decomposition of Kaolinite, Brucite, and $\mathrm{BaCO}_{3}$. J. Am. Ceram. Soc. 2, 74-77.

Hardiman, K.M., Cooper, C.G., Adesina, A.A., Lange, R., 2006. Post-mortem characterization of coke-induced deactivated alumina-supported Co-Ni catalysts. Chem. Eng. Sci. 61, 2565-2573.

Hossain, M.M., de Lasa, H.I., 2007. Reactivity and stability of $\mathrm{Co}-\mathrm{Ni} / \mathrm{Al}_{2} \mathrm{O}_{3}$ oxygen carrier in multicycle CLC. AIChE J. 53, 1817-1829.

Hossain, M.M., de Lasa, H.I., 2008. Chemical-looping combustion (CLC) for inherent image separations-a review. Chem. Eng. Sci. 63, 4433-4451.

Hossain, M.M., Quddus, M.R., de Lasa, H.I., 2010a. Reduction kinetics of La modified $\mathrm{NiO} / \mathrm{La}-\gamma \mathrm{Al}_{2} \mathrm{O}_{3}$ oxygen carrier for chemical-looping combustion. Ind. Eng. Chem. Res. 49, 11009-11017.

Hossain, M.M., de Lasa, H.I., 2010b. Reduction and oxidation kinetics of Co-Ni/ $/ \mathrm{Al}_{2} \mathrm{O}_{3}$ oxygen carrier involved in a chemical-looping combustion cycles. Chem. Eng. Sci. 65, 98-106.

Jirátová, K., Mikulová, J., Klempa, J., Grygar, T., Bastl, Z., Kovanda, F., 2009. Modification of $\mathrm{Co}-\mathrm{Mn}-\mathrm{Al}$ mixed oxide with potassium and its effect on deep oxidation of VOC. Appl. Catal. A 361, 106-116.

Kaliaguine, S., Van Neste, A., Szabo, V., Gallot, J.E., Bassir, M., Muzychuk, R., 2001. Perovskite-type oxides synthesized by reactive grinding: Part I. Preparation and characterization. Appl. Catal. A 209, 345-358.

Kim, H.W., Kang, K.M., Kwak, H.Y., 2009. Preparation of supported Ni catalysts with a core/shell structure and their catalytic tests of partial oxidation of methane. Int. J. Hydrog. Energy 34, 3351-3359.

Lario, A.L.G., Martínez, I., Murillo, R., Grasa, G., Fernandez, J.R., Abanades, J.C., 2013. Reduction kinetics of a high load $\mathrm{Cu}$-based pellet suitable for $\mathrm{Ca} / \mathrm{Cu}$ chemical 
loops. Ind. Eng. Chem. Res. 52, 1481-1490.

Liu, H.M., Sullivan, R.M., Hanson, J.C., Grey, C.P., Martin, J.D., 2001. Kinetics and mechanism of the $\beta$ - to $\alpha$-CuAlCl$l_{4}$ phase transition: a time-resolved ${ }^{63} \mathrm{Cu}$ MAS NMR and powder X-ray diffraction study. J. Am. Chem. Soc. 123, 7564-7573.

Luo, M., Wang, S.Z., Wang, L.F., Lv, M.M., 2014. Reduction kinetics of iron-based oxygen carriers using methane for chemical-looping combustion. J. Power Sources 270, 434-440.

Mihai, O., Chen, D., Holmen, A., 2011. Catalytic consequence of oxygen of lanthanum ferrite perovskite in chemical looping reforming of methane. Ind. Eng. Chem. Res. 50, 2613-2621.

Mihai, O., Chen, D., Holmen, A., 2012. Chemical looping methane partial oxidation: the effect of the crystal size and O content of $\mathrm{LaFeO}_{3}$. J. Catal. 293, 175-185.

Monazam, E.R., Breault, R.W., Siriwardane, R., Richards, G., Carpenter, S., 2013. Kinetics of the reduction of hematite $\left(\mathrm{Fe}_{2} \mathrm{O}_{3}\right)$ by methane $\left(\mathrm{CH}_{4}\right)$ during chemical looping combustion: a global mechanism. Chem. Eng. J. 232, 478-487.

Nalbandian, L., Evdou, A., Zaspalis, V., 2011. $\mathrm{La}_{1-\mathrm{x}} \mathrm{Sr}_{\mathrm{x}} \mathrm{M}_{\mathrm{y}} \mathrm{Fe}_{1-\mathrm{y}} \mathrm{O}_{3-\delta}$ perovskites as oxygen-carrier materials for chemical-looping reforming. Int. J. Hydrog. energy 36, 6657-6670.

Nasr, S., Plucknett, K.P., 2014. Kinetics of iron ore reduction by methane for chemical looping combustion. Energy Fuels 28, 1387-1395.

Neal, L.M., Shafiefarhood, A., Li, F.X., 2014. Dynamic methane partial oxidation using a $\mathrm{Fe}_{2} \mathrm{O}_{3} @ \mathrm{La}_{0.8} \mathrm{Sr}_{0.2} \mathrm{FeO}_{3-\delta}$ core-shell redox catalyst in the absence of gaseous oxygen. ACS Catal. 4, 3560-3569.

Neal, L.M., Shafiefarhood, A., Li, F.X., 2015. Effect of core and shell compositions on $\mathrm{MeO}_{\mathrm{x}} @ \mathrm{La}_{\mathrm{y}} \mathrm{Sr}_{1-\mathrm{y}} \mathrm{FeO}_{3}$ core-shell redox catalysts for chemical looping reforming of methane. Appl. Energy. http://dx.doi.org/10.1016/j.apenergy.2015.06.028

Otsuka, K., Wang, Y., Nakamura, M., 1999. Direct conversion of methane to synthesis gas through gas-solid reaction using $\mathrm{CeO}_{2}-\mathrm{ZrO}_{2}$ solid solution at moderate. Appl. Catal. A 183, 317-324.

Piekiel, N.W., Egan, G.C., Sullivan, K.T., Zachariah, M.R., 2012. Evidence for the predominance of condensed phase reaction in chemical looping reactions between carbon and oxygen carriers. J. Phys. Chem. C 116, 24496-24502.

Rashidi, H., Ebrahim, H.A., Dabir, B., 2013a. Application of random pore model for synthesis gas production by nickel oxide reduction with methane. Energ. Convers. Manag. 74, 249-260.

Rashidi, H., Ebrahim, H.A., Dabir, B., 2013b. Reduction kinetics of nickel oxide by methane as reducing agent based on thermogravimetry. Thermochim. Acta $561,41-48$.

Rostrup-Nielsen, J.R., Ertl, G., Knozinger, H., Schuth, F., Weitkamp, J. (Eds.), 2008. Handbook of Heterogeneous Catalysis. Wiley, New York, p. 2882.

Rydén, M., Lyngfelt, A., Mattisson, T., 2008a. Chemical-looping combustion and chemical-looping reforming in a circulating fluidized-bed reactor using $\mathrm{Ni}$ based oxygen carriers. Energy Fuels 22, 2585-2597.

Rydén, M., Lyngfelt, A., Mattisson, T., Chen, D., Holmen, A., Bjørgum, E., 2008b. Novel oxygen-carrier materials for chemical-looping combustion and chemicallooping reforming; $\mathrm{La}_{\mathrm{x}} \mathrm{Sr}_{1-\mathrm{x}} \mathrm{Fe}_{\mathrm{y}} \mathrm{CO}_{1-\mathrm{y}} \mathrm{O}_{3-\text { delta }}$ perovskites and mixed-metal oxides of $\mathrm{NiO}, \mathrm{Fe}_{2} \mathrm{O}_{3}$ and $\mathrm{Mn}_{3} \mathrm{O}_{4}$. Int. J. Greenh. Gas. Control 2, 21-36.

Sarshar, Z., Kaliaguine, S., 2013. Reduction kinetics of perovskite-based oxygen carriers for chemical looping combustion. Ind. Eng. Chem. Res. 52, 6946-6955.

Sedor, K.E., Hossain, M.M., de Lasa, H.I., 2008. Reduction kinetics of a fluidizable nickel-alumina oxygen carrier for chemical-looping combustion. Can. J. Chem. Eng. 86, 323-334.

Shafiefarhood, A., Galinsky, N., Huang, Y., Chen, Y., Li, F., 2014. $\mathrm{Fe}_{2} \mathrm{O}_{3} @ \mathrm{La}_{\mathrm{x}} \mathrm{Sr}_{1-\mathrm{x}} \mathrm{FeO}_{3}$ core-shell redox catalyst for methane partial oxidation. ChemCatChem 6 , 790-799.

Tanaka, H., Kaino, R., Okumura, K., Kizuka, T., Tomishige, K., 2009. Catalytic performance and characterization of $\mathrm{Rh}-\mathrm{CeO}_{2} / \mathrm{MgO}$ catalysts for the catalytic partial oxidation of methane at short contact time. J. Catal. 268, 1-8.

Tang, M.C., Xu, L., Fan, M.H., 2015. Progress in oxygen carrier development of methane-based chemical-looping reforming: a review. Appl. Energy 151, 143-156.

Velichkova, M.M., Lazarova, T., Tumbalev, V., Ivanov, G., Kovacheva, D., Stefanov, P., Naydenov, A., 2013. Complete oxidation of hydrocarbons on $\mathrm{YFeO}_{3}$ and $\mathrm{LaFeO}_{3}$ catalysts. Chem. Eng. J. 231, 236-244.

Zafar, Q., Abad, A., Mattisson, T., Gevert, B., Strand, M., 2007. Reduction and oxidation kinetics of $\mathrm{Mn}_{3} \mathrm{O}_{4} / \mathrm{Mg}-\mathrm{ZrO}_{2}$ oxygen carrier particles for chemical-looping combustion. Chem. Eng. Sci. 62, 6556-6567.

Zeng, Y., Tamhankar, S., Ramprasad, N., Fitch, F., Acharya, D., Wolf, R., 2003. A novel cyclic process for synthesis gas production. Chem. Eng. Sci. 58, 577-582.

Zhu, X., Li, K.Z., Wei, Y.G., Wang, H., Sun, L.Y., 2014. Chemical-looping steam methane reforming over a $\mathrm{CeO}_{2}-\mathrm{Fe}_{2} \mathrm{O}_{3}$ oxygen carrier: Evolution of its structure and reducibility. Energy Fuels 28, 754-776. 